\title{
STAGING OF IDIOPATHIC PULMONARY FIBROSIS
}

\section{* Tomoo Kishaba}

Department of Respiratory Medicine, Okinawa Chubu Hospital, Miyazato 281, Uruma City, Okinawa, Japan

\section{A R T I C L E I N F O}

\section{Article History:}

Received $10^{\text {th }}$ December, 2016

Received in revised form $6^{\text {th }}$ January, 2017

Accepted $26^{\text {th }}$ February, 2017

Published online $28^{\text {th }}$ March, 2017

\section{Key words:}

Staging, Idiopathic Pulmonary Fibrosis, highresolution computed tomography, forced vital capacity, Composite physiologic index, GenderApe-Physiology index, real management. \begin{abstract}
A B S T R A C T
Idiopathic Pulmonary Fibrosis (IPF) is relentless progressive interstitial lung disease (ILD) of unknown etiology (1). Main pathogenesis is aberrant recovery of epithelial injury and collagen deposition (2). Majority of IPF patients have been elderly men with smokers (3). The older, the more often have IPF (4).

Clinical point of view, non-productive cough, and progressive exertional dyspnea are main symptoms. In addition, scalene muscle hypertrophy, fine crackles and finger clubbing key findings (5).Serum marker such as lactate dehydrogenase (LDH), Krebs van den Lungeng-6 (KL-6) are sensitive for ILD detection and activity. Pulmonary function test (PFT) and 6-minute walk test (6MWT) are quite meaningful physiological examination. International IPF guideline published recently and highlighted on the importance of high-resolution computed tomography (HRCT) findings. Key findings of IPF are honeycombing, traction bronchiectasis and subpleural reticular opacity. However, baseline clinical physiological status can predict future prognosis of IPF. Recently some composite index were proposed for mortality prediction of IPF patients.In management, two anti-fibrotic agents such as pirfenidone and nintedanib are available for prevention of progression of IPF. In this review, I focus on clinical characteristics, staging and real management of IPF including comorbidities.
\end{abstract}

Copyright $@ 2017$ Tomoo Kishaba. This is an open access article distributed under the Creative Commons Attribution License, which permits unrestricted use, distribution, and reproduction in any medium, provided the original work is properly cited.

\section{INTRODUCTION}

IPF is irreversible progressive interstitial lung disease of unknown etiology $(1,2)$. IPF occurs usually elderly people over 50 with smoking history $(3,4)$. For diagnosis, chronic nonproductive cough and progressive exertional dyspnea with typical HRCT and pathological usual interstitial pneumonia (UIP) are essential. International guideline especially insist on the importance of HRCT findings such as subpleural distribution and honeycombing recently (3, 4). The pathological point of view, UIP is associated with many clinical conditions $(1,6)$. Therefore, multi-disciplinary discussion including clinicians, radiologists and pathologists is important for diagnosis of IPF (3).

\section{Clinical manifestations Symptoms}

Non-productive cough and progressive exertional dyspnea are key symptoms in IPF. Cough sometimes worse both on exercise and at night (7).

\section{*Corresponding author: Tomoo Kishaba} Department of Respiratory Medicine, Okinawa Chubu Hospital, Miyazato 281, Uruma City, Okinawa, Japan
Understanding triggering situation is important. In addition, cough predict disease progression (OR 4.97, 95\% CI: 1.25 $19.80, \mathrm{P}=0.02$ ) independent of disease severity, and may predict time to death or lung transplantation (HR 1.78, 95\% CI: $0.94-3.35, \mathrm{P}=0.08)(8)$. Cough is associated with quality of life in IPF (9). When patient report more cough and heartburn on supine, we suspect gastroesophageal reflux and IPF (10). Regarding dyspnea, we should evaluate modified Medical Research Council dyspnea scale (11). Tracing the grade of dyspnea over time is quite important for IPF patients.Sensation of change of dyspnea grade is associated with forced vital capacity (FVC) (12).

\section{Physical findings}

General appearance is important for evaluation of nutritional status and body mass index (BMI) is associated with breathing workload. Neck have much useful information of chronic lung disease. Patients with moderate to severe restrictive disorder which often have hypertrophy of scalene muscle. Use of scalene muscle is prominent when patient develop acute exacerbation (5). Typical auscultation bilateral fine crackles $(13,14)$. Fine crackles are early findings of ILD before fibrotic changes are detected by CT scan $(15,16)$. If IPF progress, crackles are heard from base to upper zones 
(17). Extent of fine crackles have often have positive correlation with area of fibrosis in HRCT. Squawk is short phase high-pitched mixed sound including musical and nonmusical sound. It is often heard chronic hypersensitivity pneumonitis (CHP) (18) and combined pulmonary fibrosis and emphysema (CPFE). Finger clubbing means chronicity of disease process. Approximately one third to half of IPF patients have clubbing. For ruling out important differential diagnosis, such as connective tissue disease (CTD), we should check arthralgia, myalgia, mechanic's hand and specific rash such as heliotrope rash and Gottron sign.

\section{Laboratory findings}

Classically, serum LDH is useful marker for activity of IPF and helpful parameter of severity of acute exacerbation (AE) of IPF (19). During acute phase, LDH is more sensitive for treatment response.KL-6 is reported to be a sensitive marker for ILD activity recently. KL-6 is associated with fibrotic area of HRCT and future exacerbation of IPF $(20,21)$. Other epithelial or macrophage-related proteins such as surfactant protein-A(SP-A), SP-D, chemokine ligand-18(CCL18) and matrixmetalloproteinase-7(MMP-7) are associated with reduced survival (22-25). SP-D often have positive association with extent of ground-glass opacity (GGO) and negative association with percent FVC. Combined product of KL-6 and SP-D was found to highly correlate with \%VC and $\%$ TLC. And this product are good indicators of the presence of fibrotic lesion in emphysema patients (26).

\section{Pulmonary function test}

FVC is robust parameter for prediction of mortality of IPF and is used as primary endpoint of many clinical trials in IPF (11). FVC is reliable, reproducible important indicator of future prediction in IPF (27). Reduction of FVC over 6 months predicts 1-year mortality. Minimal clinically important difference (MCID) of FVC absolute change is 2$6 \%$.In the meantime, absolute change of $\mathrm{FVC}$ is used. However, if we identify over $10 \%$ decline in FVC patients, choosing relative change is not different (28). Diffusing capacity for carbon monoxide (DLco) is another important physiological parameter for IPF. However, if patient's vital capacity under $1500 \mathrm{ml}$, the value is not reliable with single breath method. In addition, it is affected by respiratory infections, anemia. Therefore, reproducibility is not enough. 6 Minute walk test (6MWT) is classic physiological test for chronic lung disease. It is weakly correlated with other physiological function. In addition, 24-week decline of greater than $50 \mathrm{~m}$ in 6 MWT distance predict mortality (29). The estimated MCID of 6 MWT distance is $24-45 \mathrm{~m}$.

\section{Radiological findings \\ Chest radiograph}

It is useful for evaluation of disease distribution and serial change of volume loss especially in lower lung field. Comparison of previous film is important for decision to start aggressive treatment. Imaging based volume loss sometimes precedes decline of FVC. In addition, IPF patients often have pulmonary hypertension $(\mathrm{PH})$ in advanced stage. In these status, change of cardio-thoracic ratio and prominence of bilateral hilum are important information.

\section{HRCT findings}

HRCT provide useful information about anatomical location of disease process and key findings of IPF such as reticular opacity, traction bronchiectasis and honeycombing $(4,30)$. Honeycombing is manifested on HRCT as clustered cystic airspaces, typically of comparable diameters on the order of $3-10 \mathrm{~mm}$. It is usually located subpleural and characterized by well-defined walls (31). And both peripheral linear shadow in upper lung field and heterogeneity are important findings of IPF. When we see atypical findings, we consider alternative diagnosis or require pathology for definite diagnosis. Both micronodules and air trapping suggest CHP. Extensive GGO, peri-broncho vascular predominant distribution suggests nonspecific interstitial pneumonia (NSIP) and CTDassociated ILD. And multi-focal peripheral consolidation is associated with organizing pneumonia (OP). If we see undetermined pattern, HRCT provide adequate site for surgical lung biopsy for definitive diagnosis. Integration of clinical and imaging information contributes to final diagnosis.

\section{Bronchoalveolar lavage (BAL)}

BAL is helpful for ruling out infection, diagnosis of granulomatous lung disease and prediction of treatment response. It is quite useful especially in AE of IPF. Because advanced stage patients, it is very difficult to distinguish infection from $\mathrm{AE}$ with only clinical information. Bronchoalveolar lavage fluid (BALF) cellular analysis provide additive information for evaluation of ILD. In smokers, alveolar macrophages are predominant. In typical IPF patients, cell populations are usually normal or neutrophils predominant. When we see BALF lymphocytosis over $30 \%$ with similar presentation of IPF, we consider the possibility of CHP, NSIP, or fibrotic sarcoidosis $(32,33)$. Regarding CD4/CD 8 ratio, acute HP is usually decreased. On the other hand that is elevated for CHP and sarcoidosis (34). In BALF eosinophilia, eosinophilic pneumonia or drug associated ILD is possible (35). BALF analyses have some limitations. However, when we see ILD patients. In AE of IPF, BALF biomarkers such as KL-6, thrombomodulin have potentials to predict mortality and treatment response (36).

\section{Pathological findings}

Among the IPF patients, approximately one-third of patients have atypical presentation both clinical symptoms and HRCT findings (37). In these cases, we think surgical lung biopsy for definite diagnosis $(3,38)$. When we perform video-assisted thoracic surgery, we should take at least two or three specimens from different lobes. Especially choosing less intense area is very crucial for prediction of disease activity. However, some patients have contraindication for surgery such as pulmonary hypertension, severe heart failure and advanced age. Or patient reject this procedure. Without surgical procedure in undetermined cases, clinicians should decide whether or not to do aggressive treatment based on disease behavior (38). International guideline showed main histological IPF/UIP pattern. These findings are as follows: honeycombing a predominantly subpleural or para-septal distribution, patchy involvement of lung parenchyma by fibrosis, presence of fibroblastic foci and absence of features against a diagnosis of UIP (38). When we see UIP pattern with lymphoid aggregates with germinal centers, extensive pleuritis, prominent plasmacytic infiltration and dense perivascular collagen, lung dominant CTD is possible (39). I In this situation, we carefully follow future development of CTD. If we see centrilobular fibrosis, bridging fibrosis, 
bronchiolitis with granuloma, we should think about CHP (40). In NSIP usually show diffuse homogeneous fibrosis with temporal uniformity and preserve architecture. In addition, honeycombing is absent or scant, after obtained pathological information, multidisciplinary discussion is able to compensate for the weakness of each diagnostic process and lead to practical diagnosis with sharing key information (41).

\section{Clinical staging}

\section{Chronic phase}

Staging of IPF is useful for physicians and patients. Traditionally, clinical, radiographic, and physiologic (CRP) scoring system for IPF was proposed (42). High CRP score correlated significantly with the total pathology score including cellular and fibrotic score $(\mathrm{r}=0.61 . \mathrm{p}<0.001)$. However, CRP score was derived from many variables such as dyspnea, chest radiograph, spirometry, lung volume, diffusion capacity, resting alveolar-arterial $\mathrm{PaO} 2$, and exercise $\mathrm{O} 2$ saturation (43). Therefore, this score is complicated and not applicable easily in real world. Staging should be simple and easy to use in clinical practice. Wells, et al. proposed composite physiologic index (CPI) especially for IPF with emphysema (44). CPI consists of only major PFT parameters such as \%FVC, \% DLco, and \%FEV1. $(45,46)$. CPI reflect morphologic extent of emphysema $(47,48)$. High CPI index is associated with severity of fibrosis. Over 50 of CPI have positive relationship with mortality (49). Therefore, threshold 50 in CPI is useful for prediction of mortality of IPF. In addition, 5 point increase in CPI over 12 months predicts mortality similarly to declines of $10 \%$ in $\mathrm{FVC}$ or $15 \%$ in DLco. (HR 2.1, p=0.004) (50). Ley, et al. reported GenderAge-Physiology (GAP) Index for staging of IPF recently. GAP Index includes gender, age, \%FVC, and \% DLco. They stratified three stages and showed significant difference of 1year mortality (stages I, II, and III, 6\%, 16\%, and 39\%, respectively) (51). These difference confirmed both derivation cohort and validation cohort.(Table 1) This index is simple and applicable not only tertiary center but also general hospital $(52,53)$. And GAP index was valuable as a measure of IPF severity (54-59). Presence of Velcro Crackles is associated with high score of GAP in IPF (60). However, there was no significant difference in survival between Stages II and III, and the mortality rates in the patients classified into the GAP Stages I and II were underestimated in Japanese cohort $(61,62)$. Homma, et al. reported usefulness of Japanese severity

Table 1 Staging of chronic phase of Idiopathic Pulmonary Fibrosis

\begin{tabular}{|c|c|c|c|c|}
\hline Index & Variables & Advantage & Disadvantage & Easiness \\
\hline $\begin{array}{c}\text { JRS } \\
\text { system }\end{array}$ & $\begin{array}{c}\text { Pa02,6MWT, } \\
\text { SpO2 }\end{array}$ & $\begin{array}{c}\text { Good } \\
\text { relationship } \\
\text { with } \\
\text { survival }\end{array}$ & $\begin{array}{c}\text { Slightly } \\
\text { invasive }\end{array}$ & $\begin{array}{c}\text { Rather } \\
\text { complicated }\end{array}$ \\
\hline CPI & $\begin{array}{c}\% \text { FVC,\%DLco, } \\
\% \text { FEV1 }\end{array}$ & $\begin{array}{c}\text { Avoid } \\
\text { effect of } \\
\text { emphysema }\end{array}$ & $\begin{array}{c}\text { Underestimate } \\
\text { of obstructive } \\
\text { disorder }\end{array}$ & Proper \\
\hline GAP & $\begin{array}{c}\text { Gender, Age, } \\
\% \text { FVC, } \\
\% D L c o\end{array}$ & Simple & $\begin{array}{c}\text { Underestimate } \\
\text { of severe } \\
\text { group }\end{array}$ & Easy \\
\hline
\end{tabular}

Definition of abbreviations: JRS=Japanese Respiratory Society; $\mathrm{CPI}=$ Composite Physiologic Index; GAP $=$ Gender, Age, Physiology; $\mathrm{PaO} 2=$ Partial pressure of arterial oxygen; $6 \mathrm{MWT}=6$ minute walk test; $\mathrm{SpO} 2=$ peripheral capillary oxygen saturation; $\mathrm{FVC}=$ forced vital capacity; DLco=diffusion capacity of the lung carbon monoxide; FEV1=forced expiratory volume I second. system of IPF (63). (Table 2) They showed clear difference of survival based on stage. In addition, baseline partial pressure of arterial oxygen, vital capacity, and diffusing capacity for carbon monoxide are highly correlated with survival and stage. According to this report, more severe stage, more often have acute exacerbation (AE). In IPF, FVC is robust predictor of mortality. Therefore, combined blood gas value and GAP index is interesting predictor of mortality in IPF patients.

Table 2 Japanese severity system of Idiopathic Pulmonary Fibrosis

\begin{tabular}{|c|l|}
\hline Stage & Definition \\
\hline I & $\begin{array}{l}\mathrm{PaO} 2 \geqq 80 \mathrm{mmHg} \text { without } \\
\text { desaturation }<90 \% \text { in } 6 \mathrm{MWT}\end{array}$ \\
\hline II & $\begin{array}{l}70 \leqq \mathrm{PaO} 2<80 \mathrm{mmHg} \text { or } \mathrm{PaO} 2>80 \mathrm{mmHg} \\
\text { with desaturation }<90 \% \text { in } 6 \mathrm{MWT}\end{array}$ \\
\hline III & $\begin{array}{l}60 \leqq \mathrm{PaO} 2<70 \mathrm{mmHg} \text { or } \mathrm{PaO} 2>70 \mathrm{mmHg} \\
\text { with desaturation }<90 \% \text { in } 6 \mathrm{MWT}\end{array}$ \\
\hline IV & $\mathrm{PaO} 2<60 \mathrm{mmHg}$ \\
\hline
\end{tabular}

Definition of abbreviations: $\mathrm{PaO} 2=$ Partial pressure of arterial oxygen; $6 \mathrm{MWT}=6$ minute walk test

\section{Acute phase}

In AE of IPF patients, Akira proposed radiological staging. They reviewed 64 episodes of 58 patients with IPF. A semiquantitative analysis of overall extent of parenchymal abnormalities, extent of alveolar opacity (ground-glass attenuation and consolidation), and extent of fibrotic opacity (reticulation and honeycombing) on CT was performed. They included 34 patients of peripheral pattern, 8 of multifocal pattern, and 16 of diffuse pattern. On multivariate analysis, the strongest correlations were observed between CT patterns (combined diffuse and multifocal versus peripheral) and survival (odds ratio, 4.629; 95\% confidence interval, 1.90011.278; $\mathrm{P}=0.001)$ (64). Kishaba, et al. reported clinical staging of AE of IPF. They observed 58 episodes of AE in IPF. They showed extensive stage had poor prognosis compared to limited stage with variables of serum LDH, KL6 , ratio of partial pressure of oxygen and fraction of inspiratory oxygen, and total extent of abnormal findings on HRCT of the chest (19). (Table 3)

\section{Management Clinical trials}

We had the result of three important clinical trials recently. First, phase III trial of pirfenidone showed there was a relative reduction of $47.9 \%$ in the proportion of patients who had an absolute decline of 10 percentage points or more in the

Table 3 Staging of acute exacerbation of Idiopathic Pulmonary Fibrosis

\begin{tabular}{|c|c|c|c|c|}
\hline Staging & Variables & Advantage & Disadvantage & Easiness \\
\hline $\begin{array}{l}\text { Akira } \\
\text { staging }\end{array}$ & $\begin{array}{c}\text { HRCT, } \\
\text { peripheral, } \\
\text { multi-focal, } \\
\text { diffuse }\end{array}$ & $\begin{array}{l}\text { Non- } \\
\text { invasive }\end{array}$ & $\begin{array}{l}\text { Without clinical } \\
\text { information }\end{array}$ & $\begin{array}{l}\text { Training } \\
\text { required }\end{array}$ \\
\hline $\begin{array}{l}\text { Kishaba } \\
\text { Staging }\end{array}$ & $\begin{array}{c}\text { LDH, P/F ratio, } \\
\text { HRCT extent }\end{array}$ & $\begin{array}{l}\text { Positive } \\
\text { relationship } \\
\text { with } \\
\text { survival }\end{array}$ & $\begin{array}{c}\text { Slightly } \\
\text { complicated }\end{array}$ & Practical \\
\hline
\end{tabular}

Definition of abbreviations: HRCT=High resolution computed tomography; $\mathrm{LDH}=$ Lactate dehydrogenase; $\mathrm{P} / \mathrm{F}$ ratio=Ratio of arterial oxygen partial pressure to fractional inspired oxygen.

percentage of the predicted FVC or who died over 52 weeks $(\mathrm{P}<0.001)$ (65). In addition, pirfenidone had significant effect on reduction for death from any cause $(\mathrm{P}=0.01)$ and from IPF 
$(\mathrm{P}=0.006)$. Obstructive component was strictly excluded and target population were mild to moderate restrictive disorder in this study. In terms of adverse effect, nausea and rash were common. Both UV exposure and smoking should be avoided.

Second, the result of phase III two trial of nintedanib which is named INPULSIS-1 and INPULSIS-2were available. In this study, the adjusted annual rate of change in FVC was -114.7 $\mathrm{ml}$ with nintedanib versus $-239.9 \mathrm{ml}$ with placebo (difference, $125.3 \mathrm{ml} ; 95 \%$ confidence interval [CI], 77.7 to 172.8 ; $\mathrm{P}<0.001)$ in INPULSIS- 1 and $113.6 \mathrm{ml}$ with nintedanib versus $-207.3 \mathrm{ml}$ with placebo (difference, $93.7 \mathrm{ml}$ per year; $95 \%$ CI, 44.8 to $142.7 ; \mathrm{P}<0.001$ ) in INPULSIS-2. And INPULSIS2 , there was a significant benefit with nintedanib versus placebo about $\mathrm{AE}$ (hazard ratio, $0.38 ; 95 \% \mathrm{CI}, 0.19$ to 0.77 ; $\mathrm{P}=0.005$ ) (66). The most frequent adverse effect of nintedanib was diarrhea. However, majority of patients were controllable with anti-diarrhea drug or dose reduction. Third, Nacetylcysteine treatment of IPF patients showed no significant difference in the change in FVC between the $\mathrm{N}$-acetylcysteine group and the placebo group $(-0.18$ liters and -0.19 liters, respectively over 60 weeks; $\mathrm{P}=0.77$ ) (67). If both pirfenidone and nintedanib cannot be used due to adverse effect, Nacetylcysteine may play a role for IPF. Based on recent reports, treatment with pirfenidone for 1 year resulted in clinically meaningful reductions in disease progression in patients with IPF (68). For long-term usage of pirfenidone, Bando, et al. reported that pirfenidone treatment lasted for two years or longer in 111 cases $(22.1 \%)$. The mean change in FVC was $-30 \pm 224(\mathrm{SD}) \mathrm{mL}$ in the first year of treatment, $158 \pm 258 \mathrm{~mL}$ in the second year, and $-201 \pm 367 \mathrm{~mL}$ in the third year. The FVC improved in only a small percentage of patients who received pirfenidone treatment for a long period of time. So, which patients should be received pirfenidone for a long time remains unknown.

In the two-replicate randomized Phase III INPULSIStrials in patients with IPF, Of the treated patients, 322 were Asian (nintedanib $\mathrm{n}=194$; placebo $\mathrm{n}=128$ ) and 608 were White (nintedanib $n=360$; placebo $n=248$ ). The treatment effect of nintedanib on the annual rate of decline in FVC in Asian and White patients was similar (treatment-by-subgroup interaction $\mathrm{P}=0.72$ ) and consistent with the overall population. Race did not influence the effect of nintedanib on disease progression (69). And Seven hundred twenty-three (68.1\%) patients had honeycombing and/or biopsy, and 338 (31.9\%) patients had no honeycombing or biopsy. In these subgroups, respectively, the adjusted annual rate of decline in $\mathrm{FVC}$ in patients treated with placebo was -225.7 and $-221.0 \mathrm{ml} / \mathrm{yr}$, and the nintedanib versus placebo difference in the adjusted annual rate of decline in FVC was $117.0 \mathrm{ml} / \mathrm{yr}$ (95\% confidence interval, 76.3-157.8) and $98.9 \mathrm{ml} / \mathrm{yr}$ (95\% confidence interval, 36.4161.5) in INPULSIS trials. Raghu, et al. reported that patients with IPF who had possible UIP with traction bronchiectasis on HRCT and had not undergone surgical lung biopsy had disease that progressed in a similar way, and responded similarly to nintedanib, to that of patients with honeycombing on HRCT and/or confirmation of UIP by biopsy (70).

\section{Real management}

Both pirfenidone and nintedanib are reasonable choice for mild to moderate IPF. And pirfenidone have antiinflammatory effect. Therefore, when we see IPF with inflammation component, pirfenidone is an option. In progressive deteriorating group, first three months trend of vital capacity is predictive of mortality (71). Pirfenidone may be effective for such progressive patients. Nintedanib showed definite reduction of AE of IPF. So, when we manage IPF patients who have risk factors of $\mathrm{AE}$ such as reduced FVC and never smoking, nintedanib is a strong candidate. Nintedanib is also used for active patients because of absence of photosensitivity. (Table 4)

Table 4 Management of Idiopathic Pulmonary Fibrosis

\begin{tabular}{|c|c|c|}
\hline Drug & Indication & Adverse effect \\
\hline Pirfenidone & $\begin{array}{c}50 \% \leqq \% \mathrm{FVC}, \text { disease } \\
\text { progression, inflammation } \\
\text { component }\end{array}$ & $\begin{array}{l}\text { Photosensitivity } \\
\text { Liver dysfunction }\end{array}$ \\
\hline Nintedanib & $\begin{array}{c}50 \% \leqq \% \mathrm{FVC}, \text { Risk factor } \\
\text { of } \mathrm{AE} \text { such as reduced FVC, } \\
\text { never smoker }\end{array}$ & $\begin{array}{c}\text { Diarrhea } \\
\text { Liver dysfunction, }\end{array}$ \\
\hline
\end{tabular}

Definition of abbreviations: $\mathrm{FVC}=$ forced vital capacity; $\mathrm{AE}=\mathrm{Acute}$ exacerbation.

\section{Comorbidity}

Finally, we check comorbidity such as obstructive sleep apnea(OSA), pulmonary arterial hypertension(PAH).IPF patients more often have OSA and apnea-hypopnea index have negative relationship with total lung capacity (72). OSA is manageable with nasal continuous positive airway pressure (n-CPAP). More severe IPF patients have high incidence of PAH (73). Currently, PAH-specific drugs are not approved for IPF with PAH. Therefore, we think lung transplantation in case of young age or PAH-specific drug such as sildenafil is an option for elderly patients. Collard, et al. described pulmonary infection is important comorbidity in IPF (74). And bacterial burden contributes disease progression based on recent report. IPF and cardiovascular disease such as ischemic heart disease have same risk factor including smoking. Venous thrombosis is also sometimes seen in IPF patients. So, if IPF patients undertake orthopedic or pelvic surgery, prevention of deep vein thrombosis is crucial. Gastroesophageal reflux disease (GERD) may contribute to disease progression and acute exacerbation of IPF. And unilateral fibrosis have association with microaspiration due to GERD. However, no significant relationship between GERD and IPF based on meta-analysis. There remains controversy issue of these two diseases (75). IPF patients often have lung cancer especially adjacent fibrotic tissue and most common histology is squamous cell carcinoma. IPF with lung cancer tend to have poor prognosis because of limitation of management of discovery of advanced stage. Therefore, early detection of cancer is required. In conclusion, IPF consists of heterogeneous patients. We can decide to treat depend on clinical staging. And clinicians should monitor trend of clinical parameters, imaging findings, physiological items carefully.

\section{Compliance with Ethical Standards}

Funding: None

Conflict of Interest: Tomoo Kishaba declares that I am no conflict of interest. Ethical approval: All procedures performed in studies involving human participants were in accordance with the ethical standards of the institutional and/or national research committee and with the 1964 Helsinki declaration and its later amendments or comparable ethical standards. Informed consent was obtained from all individual participants included in the study of this review. 


\section{References}

1. American Thoracic Society, European Respiratory Society. Idiopathic pulmonary fibrosis: diagnosis and treatment. International consensus statement. $\mathrm{Am} \mathrm{J}$ Respir Crit Care Med 2000; 161: 646-64.

2. American Thoracic Society, European Respiratory Society. American Thoracic Society/European Respiratory Society international multidisciplinary consensus classification of the idiopathic interstitial pneumonias. Am J RespirCrit Care Med 2002; 165 : 277-304.

3. Raghu G, Collard HR, Egan JJ, Martinez FJ, Behr J, Brown KK, et al. An Official ATS/ERS/JRS/ ALAT statement: Idiopathic pulmonary fibrosis: evidencebased guidelines for diagnosis and management. $\mathrm{Am}$ $J$ RespirCrit Care Med 2011; 183: 788-824.

4. Bando M, Sugiyama Y, Azuma A, et al. A prospective survey of idiopathic interstitial pneumonias in a web registry in Japan. Respir Investig 2015 Mar; 53(2):51-9.

5. Kishaba T. Practical management of Idiopathic Pulmonary Fibrosis. SarcoidosisVasc Diffuse Lung Dis 2015 Jul 22;32 (2):90-8.

6. Bjoraker JA, Ryu JH, Edwin MK, Myers JL,tazelaar HD, Schroeder DR, et al. Prognostic significance of histopathologic subsets in idiopathic pulmonary fibrosis. Am JRespirCrit Care Med 1998; 157:199203.

7. vanManen MJ, Birring SS, VancheriC, et al. Cough in idiopathic pulmonary fibrosis. Eur Respir Rev 2016 Sep; 25(141):278-86.

8. Ryerson CJ, Abbritti M, Ley B, Elicker BM, Jones $\mathrm{KD}$, Collard HR. Cough predicts prognosis in idiopathic pulmonary fibrosis. Respirology 2011 Aug; 16 (6): 969-75.

9. Lechtzin N, Hilliard ME, Horton MR Validation of the Cough Quality-of-Life Questionnaire in patients with idiopathic pulmonary fibrosis. Chest 2013 Jun; 143 (6): 1745-9.

10. Fahim A, Dettmar PW, Morice AH, Hart SP. Gastroesophageal reflux and idiopathic pulmonary fibrosis: a prospective study. Medicina (Kaunas) 2011; 47 (4): 200-5.

11. Mahler DA. Evaluation of clinical methods for rating dyspnea. Chest 1988; 93: 580-586.

12. Roland M. du Bois, Derek Weycker, Carlo Albera, Bradford WZ, Costabel U, KartashovA., et al. Forced Vital Capacity in Patients with Idiopathic Pulmonary Fibrosis. Am J Respir Crit Care Med 2011; 184: 1382-1389.

13. Abraham Bohadana, Gabriel Izbicki, and Steve S. Kraman. Fundamentals of Lung Auscultation. New Engl J Med 2014; 370: 744-51.

14. Cottin V, Richeldi L. Neglected evidence in idiopathic pulmonary fibrosis and the importance of early diagnosis and treatment. Eur Respire Rev 2014 Mar 1; 23 (131): 106-10.

15. Epler GR, McLoud TC, GaenslerEA, Mikus JP, Carrington CB. Normal chest roentgenograms in chronic diffuse infiltrative lung disease. $N$ Engl $J$ Med 1978; 298: 934-9.
16. alJarad N, Strickland B, BothamleyG, Lock S, Logan-Sinclair R, Rudd RM. Diagnosis of asbestosis by a time expanded wave form analysis, auscultation and high resolution computed tomography: a comparative study. Thorax 1993; 48: 347-53.

17. Cottin V, Cordier J-F. Velcro crackles: the key for early diagnosis of idiopathic pulmonary fibrosis? EurRespir J 2012;40:519-2117 Earis JE, Marsh K, Pearson MG, Ogilvie CM. The inspiratory "squawk" in extrinsic allergic alveolitis and other pulmonary fibroses. Thorax 1982; 37: 923-6.

18. Pallarés-Sanmartín A, Leiro-Fernández V, CebreiroTL, et al. Validity and reliability of the Schamroth sign for the diagnosis of clubbing. JAMA 2010 Jul 14; 304 (2): 159-61.

19. Kishaba T, Tamaki H, Shimaoka Y, Fukuyama H, Yamashiro. Staging of acute exacerbation in patients with idiopathic pulmonary fibrosis. Lung 2014 Feb; 192 (1): 141-9.

20. Fujimoto K, Taniguchi H, Johkoh $\mathrm{T}$, Kondoh Y, Ichikado K, Sumikawa $\mathrm{H}$, et al. Acute exacerbation of idiopathic pulmonary fibrosis: high-resolution CT scores predict mortality. Eur Radiol 2012 Jan; 22 (1): 83-92.

21. Satoh H, Kurishima K, Ishikawa H, Ohtsuka M. Increased levels of KL-6 and subsequent mortality in patients with interstitial lung diseases. $J$ Intern Med 2006; 260: 429-434

22. Barlo NP, van Moorsel CHM, Ruven HJT, Zanen P, van den Bosch JMM, Grutters JC. Surfactant proteinD predicts survival in patients with idiopathic pulmonary fibrosis. SarcoidosisVasc Diffuse Lung Dis 2009; 26: 155-161.

23. Kinder BW, Brown KK, McCormack FX, Ix JH, Kervitsky A, Schwarz MI, King TE Jr. Serum surfactant protein-A is a strong predictor of early mortality in idiopathic pulmonary fibrosis. Chest 2009; 135: 1557-1563.

24. Prasse A, Probst C, Bargagli E, Zissel G, Toews GB, Flaherty KR, et al. Serum CC-chemokine ligand 18 concentration predicts outcome in idiopathic pulmonary fibrosis. Am J Respir Crit Care Med 2009; 179: 717-723.

25. Prasse A, Pechkovsky DV, Toews GB, Schäfer M, Eggeling S, Ludwig C, et al. CCL18 as an indicator of pulmonary fibrotic activity in idiopathic interstitial pneumonias and systemic sclerosis. Arthritis Rheum 2007; 56: 1685-1693.

26. Chiba S, Ohta H, Abe K, et al. The Diagnostic Value of the Interstitial Biomarkers KL-6 and SP-D for the Degree of Fibrosis in Combined Pulmonary Fibrosis and Emphysema. Pulm Med 2012; 2012:492960.

27. Flaherty KR1, Martinez FJ. The role of pulmonary function testing in pulmonary fibrosis. Curr Opin Pulm Med 2000 Sep;6(5):404-10.

28. Richeldi L, Ryerson CJ, Lee JS, Wolters PJ, Koth LL, Ley B, et al.Relative versus absolute change in forced vital capacity in idiopathic pulmonary fibrosis. Thorax 2012 May; 67 (5): 407-11.

29. Roland M. du Bois, Derek Weycker, Carlo Albera, Bradford WZ, Costabel U, Kartashov A, et al. SixMinute-Walk Test in Idiopathic Pulmonary Fibrosis Test Validation and Minimal Clinically Important 
Difference. Am J RespirCrit Care Med 2011; 183: 1231-1237.

30. Johkoh T, Muller NL, Cartier Y, Kavanagh PV, Hartman TE, Akira M, et al. Idiopathic interstitial pneumonias:diagnostic accuracy of thin-section CT in 129 patients. Radiology 1999; 211: 555-560.

31. Hansell DM, Bankier AA, Macmahon H, McLoud TC, Muller NL, Remy J. Fleischner Society: Glossary of terms for thoracic imaging. Radiology 2008; 246: 697-722.

32. Hwang JH, Misumi S, Sahin H, Brown KK, Newell JD, Lynch DA. Computed tomographic features of idiopathic fibrosing interstitial pneumonia: comparison with pulmonary fibrosis related to collagen vascular disease. J Comput Assist Tomogr 2009; 33: 410-415.

33. Costabel U, Bonella F, Guzman J. Chronic hypersensitivity pneumonitis. Clin Chest Med 2012 Mar; 33 (1): 151-63.

34. Winterbauer RH, Lammert J, Selland M, Wu R, Corley D, Springmeyer SC. Bronchoalveolar lavage cell populations in the diagnosis of sarcoidosis. Chest 1993;104:352-361.

35. Costabel U, Uzaslan E, Guzman J. Bronchoalveolar lavage in drug induced lung disease. Clin Chest Med 2004; 25: 25-35.

36. Keith C. Meyer, Ganesh Raghu, Robert P. Baughman, Brown KK, Costabel U, du Bois RM, et al. An Official American Thoracic Society Clinical Practice Guideline: The Clinical Utility of Bronchoalveolar Lavage Cellular Analysis in Interstitial Lung Disease Am J Respir Crit Care Med 2012; 185 (9): 1004-1014.

37. Kim DS, Collard HR, King TE. Classification and natural history of the idiopathic interstitial pneumonias. Proc Am Thorac Soc 2006; 3:285-292.

38. Meltzer EB, Noble PW. Idiopathic pulmonary fibrosis. Orphanet J Rare Dis 2008; 3: 8-22.

39. William D. Travis, Ulrich Costabel, David M. Hansell, King TE Jr, Lynch DA, Nicholson AG, et al. An Official American Thoracic Society/European Respiratory Society Statement: Update of the International Multidisciplinary Classification of the Idiopathic Interstitial Pneumonias. Am J Respire Crit Care Med 2013; 188 (6): 733-748.

40. Aryeh Fischer, Sterling G. West, Jeffrey J. Swigris, Brown KK, du Bois RM. Connective tissue diseaseassociated interstitial lung disease: a call for clarification. Chest 2010; 138 (2): 251-256.

41. Takemura $T$, Akashi $T$, Kamiya H, Ikushima S, Ando T, Oritsu M, et al. Pathological differentiation of chronic hypersensitivity pneumonitis from idiopathic pulmonary fibrosis/usual interstitial pneumonia. Histopathology 2012; 61: 1026-1035.

42. Tabata K, Fukuoka J. Histopathologic Features of Usual Interstitial Pneumonia and Related Patterns: What is Important for Radiologists? Semin Ultrasound CT MRI 2014 35:2-11.

43. Watters LC, King TE, Schwarz MI, et al. A clinical, radiographic, and physiologic scoring system for the longitudinal assessment of patients with idiopathic pulmonary fibrosis. Am Rev Respir Dis. 1986 Jan; 133(1):97-103.
44. Tomassetti S, Ryu JH, Poletti V. Staging systems and disease severity assessment in interstitial lung diseases. Curr Opin Pulm Med. 2015 Sep; 2(5):4639.

45. Wells $\mathrm{AU}$, King $\mathrm{AD}$, Rubens $\mathrm{MB}$, et al. Lone cryptogenic fibrosing alveolitis: a functionalmorphologic correlation based on extent of disease on thin-section computed tomography. Am J Respir Crit Care Med 1997 Apr; 155(4):1367-75.

46. Wells AU, Desai SR, Rubens MB, et al. Idiopathic pulmonary fibrosis: a composite physiologic index derived from disease extent observed by computed tomography. Am J RespirCrit Care Med. 2003 Apr 1; 167(7):962-9.

47. Latsi PI, du Bois RM, Nicholson AG, et al. Fibrotic idiopathic interstitial pneumonia: the prognostic value of longitudinal functional trends. $\mathrm{Am} J$ RespirCrit Care Med. 2003 Sep 1;168(5):531-7.

48. Mura M, Zompatori M, PacilliAM, et al. The presence of emphysema further impairs physiologic function in patients with idiopathic pulmonary fibrosis. Respir Care. 2006 Mar; 51(3):257-65.

49. Desai SR1, Hansell DM, Walker A, et al. Quantification of emphysema: a composite physiologic index derived from CT estimation of disease extent. Eur Radiol. 2007 Apr; 17(4):911-8.

50. Behr J, Demedts M, Buhl R, et al. Lung function in idiopathic pulmonary fibrosis-extended analyses of the IFIGENIA trial. Respir Res. 2009 Oct 27; 10:101

51. Schmidt SL, Nambiar AM, Tayob $\mathrm{N}$, et al. Pulmonary function measures predict mortality differently in IPF versus combined pulmonary fibrosis and emphysema. Eur Respir J. $2011 \mathrm{Jul}$; 38(1):176-83.

52. Ley B, Ryerson CJ, VittinghoffE, et al. A multidimensional index and staging system for idiopathic pulmonary fibrosis. Ann Intern Med. 2012 May 15; 156(10):684-91.

53. Kolb M, Collard HR. Staging of idiopathic pulmonary fibrosis: past, present and future. Eur Respir Rev. 2014 Jun; 23(132):220-4.

54. Jo HE, Glaspole I, Grainge C, et al. Baseline characteristics of idiopathic pulmonary fibrosis: analysis from the Australian Idiopathic Pulmonary Fibrosis Registry. Eur Respir J 2017 Feb 23;49(2).

55. Fujii M, Shirai T, Mori K, et al. Inspiratory resonant frequency of forced oscillation technique as a predictor of the composite physiologic index in interstitial lung disease. Respir Physiol Neurobiol. 2015 Feb 1; 207:22-7.

56. Jacob J, Bartholmai BJ, Rajagopalan $\mathrm{S}$, et al. Mortality prediction in idiopathic pulmonary fibrosis: evaluation of computer-based CT analysis with conventional severity measures. Eur Respir $J$ 2017 Jan 25; 49(1).

57. Zhang L, Zhang C, Dong F, et al. Combined pulmonary fibrosis and emphysema: a retrospective analysis of clinical characteristics, treatment and prognosis. BMC Pulm Med. 2016 Nov 3;16(1):137.

58. Hyldgaard C, Hilberg O, Muller A, et al. A cohort study of interstitial lung diseases in central Denmark. Respir Med. 2014 May; 108(5):793-9. 
59. Kim ES, Choi SM, Lee J, et al. Validation of the GAP score in Korean patients with idiopathic pulmonary fibrosis. Chest $2015 \mathrm{Feb} ; 147(2)$ :430-7.

60. Hyldgaard C. A cohort study of Danish patients with interstitial lung diseases: burden, severity, treatment and survival. Dan Med J 2015 Apr; 62(4): B5069.

61. Sellarés J, Hernández-González F, Lucena CM, et al. Auscultation of Velcro Crackles is Associated with Usual Interstitial Pneumonia. Medicine (Baltimore). 2016 Feb; 95(5):e2573.

62. Kishaba T, Shimaoka Y, Fukuyama H, et al.Clinical characteristics of idiopathic pulmonary fibrosis patients with gender, age, and physiology staging at Okinawa Chubu Hospital. J Thorac Dis. 2015 May; 7(5):843-9.

63. Kondoh S, Chiba H, NishikioriH, et al. Validation of the Japanese disease severity classification and the GAP model in Japanese patients with idiopathic pulmonary fibrosis. Respir Investig. 2016 Sep; 54(5):327-33.

64. Homma S, Sugino K, Sakamoto S. Usefulness of a disease severity staging classification system for IPF in Japan: 20 years of experience from empirical evidence to randomized control trial enrollment. Respir Investig. 2015 Jan; 53(1):7-12.

65. Akira M, Kozuka T, Yamamoto S, et al. Computed tomography findings in acute exacerbation of idiopathic pulmonary fibrosis. Am J Respir Crit Care Med. 2008 Aug 15; 178(4):372-8.

66. Taniguchi H, Ebina M, Kondoh Y, Ogura T, Azuma A, Suga $\mathrm{M}$, et al. Pirfenidone in idiopathic pulmonary fibrosis. EurRespir J 2010; 35: 821-829.

67. Luca Richeldi, Roland M. du Bois, Ganesh Raghu, Azuma A, Brown KK, CostabelU, et al. Efficacy and Safety of Nintedanib in Idiopathic Pulmonary Fibrosis. N Engl J Med 2014; 370 (22): 2071-2082.
68. Idiopathic Pulmonary Fibrosis Clinical Research Network. Prednisone, azathioprine, and Nacetylcysteine for pulmonary fibrosis. $N$ Engl J Med 2012; 366: 1968-1977.

69. Bando $\mathrm{M}$, Yamauchi $\mathrm{H}$, Ogura $\mathrm{T}$, et al. ClinicalExperience of the Long-term Use of Pirfenidone for Idiopathic Pulmonary Fibrosis. Intern Med 2016; 55(5):443-8.

70. Taniguchi H, Xu Z, Azuma A, et al. Subgroup analysis of Asian patients in the INPULSIS $\AA$ trials of nintedanib in idiopathic pulmonary fibrosis. Respirology 2016 Nov; 21(8):1425-1430.

71. Raghu G, Wells AU, Nicholson AG, et al. Effect of Nintedanib in Subgroups of Idiopathic Pulmonary Fibrosis by Diagnostic Criteria. Am J Respir Crit Care Med. 2017 Jan 1; 195(1):78-85.

72. Taniguchi $\mathrm{H}$, Kondoh $\mathrm{Y}$, EbinaM, et al. The clinical significance of $5 \%$ change in vital capacity in patients with idiopathic pulmonary fibrosis: extended analysis of the pirfenidone trial. Respir Res $2011 \mathrm{Jul}$ $15 ; 12: 93$.

73. Mermigkis C, Stagaki E, TryfonS, et al. How common is sleep-disordered breathing in patients with idiopathic pulmonary fibrosis? Sleep Breath. 2010 Dec; 14(4):387-90.

74. Kimura M, Taniguchi H, KondohY, et al. Pulmonary hypertension as a prognostic indicator at the initial evaluation in idiopathic pulmonary fibrosis. Respiration 2013; 85(6):456-63.

75. Collard HR, Ward AJ, Lanes S, et al. Burden of illness in idiopathic pulmonary fibrosis. $J$ Med Econ.2012; 15(5):829-35.

76. Kreuter M, Wuyts W, RenzoniE, et al. Antacid therapy and disease outcomes in idiopathic pulmonary fibrosis: a pooled analysis. Lancet Respir Med. 2016 May; 4(5):381-9.

\section{Please cite this article in press as:}

Tomoo Kishaba (2017), Staging of idiopathic pulmonary fibrosis, International Journal of Current Advanced Research, 6(03), pp.3005-3011. http://dx.doi.org/10.24327/ijcar.2017. 3011.0164 